\title{
PERANCANGAN USER EXPERIENCE PADA APLIKASI MOBILE HOMECARE RUMAH SAKIT SEMEN GRESIK MENGGUNAKAN METODE DESIGN THINKING
}

\author{
Fara Regina Isadora ${ }^{* 1}$, Buce Trias Hanggara ${ }^{2}$, Yusi Tyroni Mursityo ${ }^{3}$ \\ ${ }^{1,2,3}$ Universitas Brawijaya Malang \\ Email: ${ }^{1}$ farareg@student.ub.ac.id, ${ }^{2}$ buce_trias@ub.ac.id, ${ }^{3}$ yusi_tyro@ub.ac.id \\ "Penulis Korespondensi
}

(Naskah masuk: 30 Desember 2020, diterima untuk diterbitkan: 19 Oktober 2021)

\begin{abstract}
Abstrak
Rumah Sakit Semen Gresik merupakan fasilitas kesehatan yang ada di Kabupaten Gresik dengan akreditasi tingkat paripurna. Rumah Sakit Semen Gresik di kondisi pandemi saat ini mengalami penurunan jumlah pasien dan pendapatan, sehingga Rumah Sakit Semen Gresik berencana untuk menghadirkan layanan kesehatan yang dapat dilakukan di rumah menggunakan aplikasi untuk memudahkan pasien dalam mendapatkan layanan Kesehatan tanpa datang ke rumah sakit. Aplikasi yang dibangun harus memberikan kenyamanan saat digunakan oleh pengguna, maka dari itu perlu adanya rancangan user experience. Design thinking merupakan metode yang digunakan untuk merancang user experience pada aplikasi HomeCare dengan mendefinisikan permasalahan serta memberikan solusi desain yang dapat menyelesaikan permasalahan tersebut. Solusi desain selanjutnya diuji menggunakan user experience questionnaire (UEQ) untuk mengetahui apakah solusi desain yang dirancang sudah menyelesaikan permasalahan yang dialami oleh calon pengguna. Hasil dari pengujian menggunakan UEQ yaitu, untuk aplikasi HomeCare dengan pengguna pasien memiliki nilai mean tiap skala UEQ yang berada pada kategori positif dengan semua skala UEQ berada pada kategori baik kecuali skala dependability yang berada pada kategori sangat baik, sedangkan untuk aplikasi HomeCare Giver dengan pengguna tenaga kesehatan memiliki nilai mean tiap skala UEQ yang juga berada pada kategori positif dengan semua skala UEQ berada pada kategori baik kecuali skala attractiveness dan novelty yang berada pada kategori sangat baik. Sehingga aplikasi HomeCare dan HomeCare Giver memiliki rancangan user experience yang baik.
\end{abstract}

Kata kunci: User Experience, Design Thinking, User Experience Questionnaire, Aplikasi Mobile

\section{USER EXPERIENCE DESIGN OF RUMAH SAKIT SEMEN GRESIK'S HOMECARE MOBILE APPLICATION USING THE DESIGN THINKING METHOD}

\begin{abstract}
Semen Gresik Hospital is a health facility in Gresik Regency with a paripurna level of accreditation. Semen Gresik Hospital in a pandemic condition is currently experiencing a decrease in the number of patients, so that Semen Gresik Hospital plans to provide health services that can be done at home using an application to make it easier for patients to get health services without coming to the hospital. Applications that are built must provide comfort when used by users, therefore there is a need for a user experience design. Design thinking is a method used to design user experiences on the HomeCare application by defining problems and providing design solutions that can solve these problems. The design solution is then tested using a user experience questionnaire $(U E Q)$ to find out whether the design solution designed has resolved the problems experienced by potential users. The results of the test using UEQ are, for the HomeCare application whose users are patient, the mean value of each UEQ scale is in the positive category with all UEQ scales in the good category except for the dependability scale which is in the very good category, while for the HomeCare Giver application whose the users are health workers, has a mean value of each UEQ scale which is also in the positive category with all $U E Q$ scales in the good category except the attractiveness and novelty scales which are in the very good category. This can be concluded that HomeCare and HomeCare Giver applications have a good user experience design.
\end{abstract}

Keywords: User Experience, Design Thinking, User Experience Questionnaire, Mobile Application 


\section{PENDAHULUAN}

Teknologi saat ini menjadi alat bantu masyarakat khususnya pada layanan publik, salah satu layanan publik tersebut yaitu pada bidang kesehatan. Dalam bidang kesehatan, beberapa pelayan kesehatan seperti klinik, rumah sakit, dan fasilitas kesehatan lainnya sudah menerapkan teknologi dalam mendukung kegiatan operasionalnya. Dalam penerapan teknologi, Rumah Sakit Semen Gresik menjadi salah satu fasilitas kesehatan yang berusaha menghadirkan layanan yang memudahkan masyarakat.

Rumah Sakit Semen Gresik (RS Semen Gresik) merupakan salah satu rumah sakit yang berada di Kabupaten Gresik, Jawa Timur. Sesuai dengan misinya, Rumah Sakit Semen Gresik selalu meningkatkan kualitas pelayanannya dengan mengutamakan kecepatan, ketepatan, dan keselamatan. Pada kenyataannya, dengan kondisi pandemi saat ini, masyarakat enggan untuk datang ke rumah sakit karena takut tertular virus COVID-19 dan membahayakan keselamatan masyarakat serta lingkungan mereka. Hal tersebut juga terjadi pada Rumah Sakit Semen Gresik, semula pasien pada Rumah Sakit Semen Gresik dapat melebihi angka 600 orang per hari, karena kondisi pandemi seperti saat ini, jumlah pasien pada Rumah Sakit Semen Gresik turun drastis menjadi sekitar 200 orang per harinya (Sucahyo, 2020). Dengan hal tersebut, Rumah Sakit Semen Gresik berusaha menghadirkan layanan HomeCare yang tujuannya untuk mempermudah pasien Rumah Sakit Semen Gresik yang ingin berobat namun tidak mampu untuk pergi ke rumah sakit karena penyakit tertentu atau keadaan lain, maka dari itu Rumah Sakit Semen Gresik membutuhkan rancangan user experience dalam membangun dan mewujudkan aplikasi HomeCare agar dapat memberikan kenyamanan kepada calon penggunanya.

Dalam menyediakan layanan HomeCare yang sesuai dengan harapan pengguna, perlu dilakukan perancangan pengalaman pengguna atau user experience (UX). Perancangan UX merupakan hal yang penting untuk dilakukan ketika hendak membuat sistem, karena user experience yang dirancang dengan baik dapat memberikan kesan yang baik pula bagi penggunanya. Perancangan UX sendiri bertujuan agar nantinya aplikasi dapat memberikan pengalaman yang baik untuk penggunanya serta meningkatkan efisiensi dalam penggunaan aplikasi tersebut. Pengalaman yang baik bagi pengguna dapat meningkatkan rasa nyaman ketika pengguna menggunakan aplikasi dan memicu pengguna untuk menggunakan kembali aplikasi tersebut (Garret, 2003).

Terdapat beberapa metode pada perancangan UX yang dapat digunakan. Pada penelitian ini metode yang akan digunakan yaitu metode design thinking. Metode design thinking adalah metode perancangan UX yang memiliki lima tahapan di dalamnya. Tahap pertama adalah empathize, pada tahap ini dilakukan penggalian masalah yang ingin diselesaikan, pada tahap empathize, dapat dilakukan dengan wawancara langsung kepada pihak Rumah Sakit Semen Gresik untuk menggali informasi yang berkaitan dengan penelitian ini. Tahap kedua adalah define, pada tahap ini, hasil wawancara yang sudah dikumpulkan pada tahap empathize diolah dan dianalisis untuk menemukan masalah utama yang dijadikan landasan perancangan UX. Tahap ketiga yaitu ideate, tahapan yang berfokus pada pemberian solusi desain dari permasalahan yang telah diketahui pada tahap sebelumnya. Tahap selanjutnya adalah prototype, tahapan yang menghasilkan sebuah prototype low-fidelity dan prototype high-fidelity yang dibuat berdasarkan solusi desain yang telah didapatkan. Tahap terakhir adalah test, tahapan dimana hasil prototyping yang sudah dibuat berdasarkan solusi pada tahap sebelumnya diuji dan dievaluasi oleh calon pengguna aplikasi dengan menggunakan metode User Experience Questionnaire (UEQ), uji dan evaluasi dilakukan agar dapat diketahui apakah aplikasi tersebut sudah memberikan pengalaman penggunaan yang baik bagi penggunanya (Schrepp, et al., 2017). Dari hasil testing tersebut, dapat diketahui apakah solusi desain sudah menyelesaikan masalah dan sesuai harapan pengguna atau masih memerlukan perubahan pada solusi yang ditawarkan (Plattner, et al., 2011). Dari penjelasan sebelumnya, maka dapat disimpulkan metode design thinking dipilih karena metode tersebut berfokus pada calon pengguna, sehingga aplikasi yang dirancang dapat memberikan kepuasan yang diharapkan pengguna saat menggunakan aplikasi.

\section{METODE PENELITIAN}

Tahap penelitian adalah langkah atau tahap yang dilakukan pada penelitian agar berjalan secara terstruktur. Tahap penelitian digambarkan dengan flowchart pada Gambar 1.

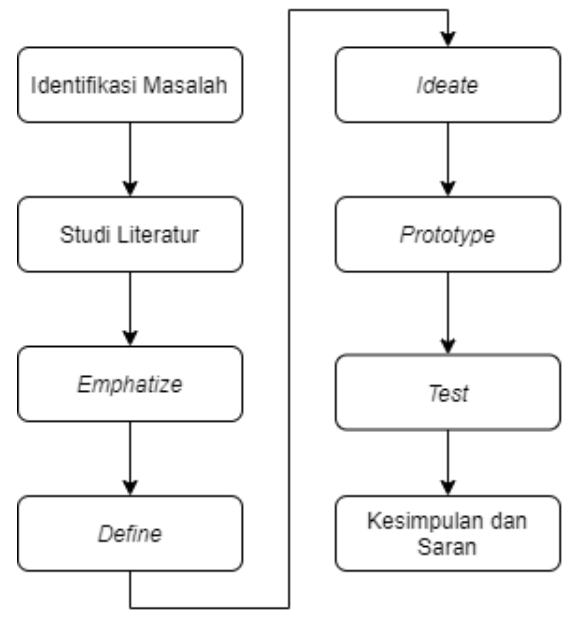

Gambar 1. Tahap Penelitian 
Identifikasi masalah adalah tahap dilakukannya penggalian masalah pada suatu objek. Identifikasi masalah dilakukan dengan cara survei langsung dan melakukan wawancara dengan pihak yang bersangkutan dengan objek yang akan diteliti.

Studi literatur merupakan hal yang sangat penting dalam penelitian guna menambah wawasan mengenai hal yang akan dilakukan pada penelitian. Studi literatur berasal dari berbagai sumber. Studi literatur yang dilakukan tentunya berkaitan dengan penelitian yang akan dilakukan seperti metode Design Thinking, User Experience, perancangan UX, dan UEQ.

Empathize yaitu tahap identifikasi calon pengguna dari produk yang akan dibuat dan melakukan wawancara terkait permasalahan yang dialami dan kebutuhan yang diperlukan. Pada tahap ini juga dibuat persona untuk memberikan penjelasan deskriptif yang dibuat secara realistis untuk menggambarkan target pengguna sebuah produk.

Selanjutnya define, pada tahap ini informasi yang sebelumnya diperoleh kemudian diolah dan dianalisis agar dapat ditemukannya permasalahan utama. Pengolahan dan analisis informasi dilakukan dengan menggunakan empathy map sebagai bentuk visualisasi yang digunakan untuk menjelaskan apa yang diketahui tentang jenis pengguna tertentu, empathy map juga membantu dalam memiliki pemahaman tentang kebutuhan pengguna dan menjadi referensi atau pertimbangan dalam mengambil sebuah keputusan. Setelah itu tahap ini juga dilakukan Point of View (POV) yang menghasilkan problem statement untuk menjelaskan siapa penggunanya, apa kebutuhan dari pengguna, dan alasan pengguna memiliki kebutuhan tersebut.

Kemudian ideate yang merupakan tahap dimana masalah yang telah didapatkan pada tahap sebelumnya diubah menjadi beberapa solusi desain yang dihasilkan melalui brainstorming tim agar semua pihak yang bersangkutan dapat menyampaikan ide atau solusi yang mereka pikirkan dan dapat disesuaikan dengan kapabilitas yang dimiliki oleh pihak Rumah Sakit Semen Gresik yang kemudian dipilih menggunakan metode post-it voting, Solusi yang memiliki tanda paling banyak berarti menjadi solusi yang banyak dipilih yang kemudian akan diimplementasikan pada tahap selanjutnya.

Setelah itu prototype yang bertujuan untuk memodelkan solusi desain yang telah dirancang sebelumnya agar dapat menggambarkan rancangan produk yang akan dibuat. Prototype adalah bentuk yang nantinya akan diuji dan dinilai pada tahap selanjutnya. Pada tahap ini, prototype dibagi menjadi 2 yaitu prototype low-fidelity dan prototype high-fidelity.

Selanjutnya test yang bertujuan untuk mengetahui apakah solusi yang telah dibuat sudah memenuhi kebutuhan pengguna. Test juga bertujuan agar dapat diketahui apakah produk yang dibuat sudah sesuai dengan tujuan awal. Test yang dilakukan pada penelitian ini menggunakan metode UEQ agar dapat diketahui pula bagaimana perasaan pengguna setelah menggunakan produk berdasarkan solusi yang telah dibuat.

Tahap terakhir yaitu kesimpulan dan saran. Pada tahap ini dilakukan penarikan kesimpulan dan juga penyusunan saran yang dapat diberikan dari hasil penelitian yang telah dilaksanakan. Penyusunan kesimpulan bertujuan untuk menjelaskan ringkasan dari penelitian yang telah dilakukan. Pemberian saran bertujuan untuk menyampaikan catatan terhadap permasalahan pada penelitian yang telah dilakukan atau pesan kepada penelitian lanjutan.

\section{LANDASAN KEPUSTAKAAN}

\subsection{Landasan Kepustakaan}

Jurnal pertama yang menjadi landasan kepustakaan yaitu oleh Aria Ar Razi, Intan Rizky Mutiaz dan Pindi Setiawan pada tahun 2018. Penelitian ini merupakan artikel dari Jurnal Desain Komunikasi Visual. Penelitian ini bertujuan untuk membuat rancangan UI/UX dari aplikasi yang bernama kembaliin. Aplikasi kembaliin berfungsi untuk memberikan dan menerima informasi terkait barang hilang. Metode perancangan UX yang digunakan pada penelitian ini yaitu metode design thinking. Hasil dari penelitian ini yaitu rancangan UI/UX produk atau aplikasi untuk mewadahi kasus barang hilang atau tercecer yang saat ini belum memiliki solusi yang dapat diandalkan. Penelitian ini dijadikan referensi dalam pemahaman mengenai metode design thinking dalam perancangan UX.

Penelitian lain yang menjadi landasan kepustakaan yaitu oleh Irma Rofni Wulandari dan Lilis Dwi Farida pada tahun 2018. Penelitian ini bertujuan untuk mengukur pengalaman pengguna dari layanan e-Learning pada Universitas XYZ. Penelitian ini menggunakan User Experience Questionnaire (UEQ) dengan 113 responden dalam mengukur pengalaman pengguna. Hasil penelitian ini yaitu interpretasi atau penafsiran dari hasil analisis yang telah dilakukan. Hasil analisis menunjukan bahwa rata-rata nilai dari layanan eLearning pada universitas XYZ cenderung dibawah rata-rata (below average), selain itu terdapat satu atribut yaitu kebaruan (novelty) yang memiliki nilai buruk (bad). Dari hasil tersebut, dapat disimpulkan bahwa masih diperlukannya peningkatan atau perbaikan User Experience pada layanan e-Learning Universitas XYZ. Penelitian ini dijadikan pemahaman dalam melakukan penilaian UX menggunakan User Experience Questionnaire (UEQ). 


\subsection{Design Thinking}

Metode design thinking adalah metode perancangan UX yang berfokus pada manusia (human-centered). Menurut Interaction Design Foundation (2020), design thinking merupakan metode yang fleksibel karena tahapan yang dilakukan pada design thinking tidak harus dilakukan secara berurutan. Selain itu, metode design thinking juga metode yang dilakukan secara iteratif karena pada prosesnya, tahapan yang dilakukan dapat diulang sampai masalah yang mendasari pelaksanaan design thinking terselesaikan. Menurut Plattner (2009), Terdapat lima tahap yang ada pada design thinking.

a. Empathize

Tahap ini Bertujuan untuk mengumpulkan sebanyak mungkin masalah yang dialami oleh pengguna.

b. Define

Tahap ini bertujuan untuk menganalisis dan menyimpulkan masalah yang sudah didapatkan. Setelah itu, masalah yang ditemukan dijadikan sebagai fokus utama penelitian. Sehingga dari masalah utama tersebut dapat ditemukannya kebutuhan.

c. Ideate

Tahap ini bertujuan untuk merubah masalah menjadi sebuah solusi. Tahap ini menghasilkan ide atau solusi untuk masalah yang sudah didapatkan pada tahapan sebelumnya.

d. Prototype

Tahap ini biasa disebut dengan rancangan awal dari ide yang sudah dibuat. Perancangan ide dituangkan dengan pembuatan prototype dibagi menjadi dua kategori yaitu prototype low-fidelity dan prototype high-fidelity.

e. Test

Tahap ini bertujuan agar dapat mengetahui pendapat pengguna mengenai solusi yang telah dibuat. Dengan terkumpulnya pendapat pengguna juga dapat dijadikan sebagai penyempurnaan prototype dan solusi yang sudah dibuat.

\subsection{User Experience}

User experience adalah apa yang dirasakan pengguna setelah menggunakan sebuah produk, atau dapat disebut dengan istilah pengalaman pengguna. User experience menjadi tolak ukur dalam kepuasan pengguna saat menggunakan produk. Kualitas produk yang baik dipengaruhi oleh user experience yang baik pula. Dengan user experience yang baik, pengguna menjadi merasa aman dan nyaman untuk menggunakan produk itu kembali. Menurut ISO 9241-210 (2009), UX dapat diartikan sebagai persepsi dan respon dari pengguna terhadap sebuah produk atau jasa.

\subsection{User Experience Questionnaire}

User Experience Questionnaire (UEQ) adalah metode perhitungan yang digunakan untuk mengukur pengalaman pengguna terhadap sebuah sistem melalui angket berupa kuesioner yang diberikan kepada pengguna sistem. UEQ memberikan kecepatan dalam melakukan olahan hasil pengukuran pengalaman pengguna. Mengacu pada User Experience Questionnaire Handbook (2019) yang dipublikasikan pada halaman website UEQ, menjelaskan bahwa pengolahan data menggunakan UEQ dapat dilakukan dengan jumlah partisipan sebanyak $20-40$ partisipan. Dalam pengukurannya, UEQ memiliki alat untuk melakukan perhitungan yang bernama Data Analysis Tools yang disediakan UEQ untuk mempermudah perhitungan data yang telah dikumpulkan.

Kuesioner UEQ terdiri dari 6 skala penilaian yang memiliki total pertanyaan 26 item. Berikut adalah atribut penilaian pada kuesioner UEQ:

a. Attractiveness

Kesan pengguna saat pertama kali menggunakan produk tersebut.

b. Dependability

Bagaimana sebuah sistem dapat memberikan interaksi yang sesuai dengan yang diharapkan oleh pengguna.

c. Efficiency

Bagaimana pengguna dapat menyelesaikan tugas dengan sistem secara efisien.

d. Novelty

Bagaimana sebuah sistem dapat memberikan rasa menyenangkan saat digunakan oleh penggunanya.

e. Perspicuity

Bagaimana kemudahan penggunaan yang dapat diberikan sebuah sistem kepada penggunanya.

\section{f. Stimulation}

Bagaimana sistem memiliki perbedaan yang unik menurut perspektif pengguna.

\section{ANALISIS KEBUTUHAN}

\subsection{Penggalian Masalah (Empathize)}

Pada tahap empathize, dilakukan penggalian masalah dan kebutuhan dari stakeholder dan calon pengguna yang dilakukan dengan teknik wawancara. Proses design thinking harus dimulai dengan pemahaman yang mendalam terkait orang-orang yang akan dijadikan dasar dalam membuat solusi. Dalam penelitian kualitatif, jumlah responden yang dilibatkan tidak ditentukan berdasarkan besar populasi, melainkan dari jawaban yang diberikan oleh responden. Jumlah responden dapat diketahui ketika jawaban responden sudah mencapai titik jenuh dan tidak ditemukan lagi wawasan baru 
(Kusumawardani, et al., 2015), sehingga pada penelitian ini dilibatkan 10 responden sebagai pasien dan 10 responden sebagai tenaga kesehatan yang bekerja di Rumah Sakit Semen Gresik.

Dari wawancara yang telah dilakukan, diketahui bahwa kondisi pandemi saat ini memberikan dampak pada pendapatan dan jumlah pasien Rumah Sakit Semen Gresik. Hal tersebut melatarbelakangi rencana Rumah Sakit Semen Gresik dalam membuat produk layanan HomeCare berbasis aplikasi mobile. Terdapat 2 jenis aplikasi yang dibutuhkan yaitu aplikasi untuk memesan layanan kesehatan dengan target pengguna pasien Rumah Sakit Semen Gresik bernama HomeCare, dan aplikasi untuk memberikan layanan kesehatan dengan target pengguna tenaga kesehatan Rumah Sakit Semen Gresik bernama HomeCare Giver. Dari data yang telah diperoleh dari hasil wawancara ditemukan karakteristik pengguna yaitu:

a. Pengguna berjenis kelamin laki-laki atau perempuan,

b. Pengguna berusia 17-50 tahun,

c. Pengguna dari aplikasi HomeCare merupakan masyarakat Gresik yang pernah berobat dan memiliki nomor rekam medis pada Rumah Sakit Semen Gresik,

d. Pengguna dari aplikasi HomeCare Giver bekerja sebagai tenaga kesehatan di Rumah Sakit Semen Gresik.

Selanjutnya dilakukan pembuatan persona yang menjelaskan tentang kebutuhan, tujuan, dan perilaku dari calon pengguna. Selain itu, persona yang dibuat haruslah realistis, persona juga berisikan demografi dari calon pengguna seperti, nama, umur, gender, foto (Nielsen Norman Group, 2015). Dari informasi sebelumnya, dibuat persona untuk pengguna pasien dan tenaga kesehatan. Gambar 2 merupakan salah satu contoh persona untuk pengguna pasien.

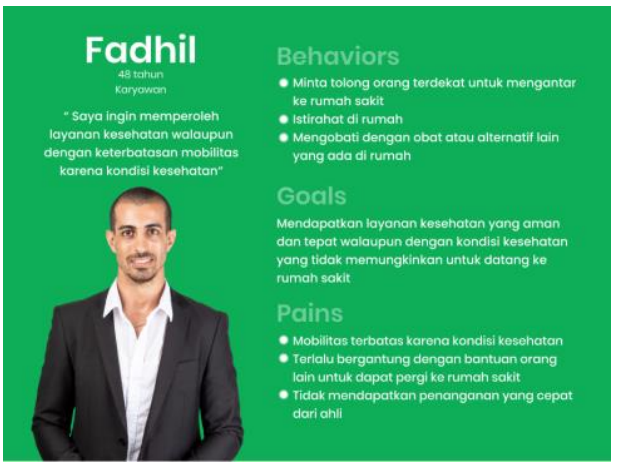

Gambar 2. Persona Pasien

Untuk contoh persona pasien yaitu seorang laki-laki berumur 48 tahun bernama Fadhil. Fadhil ingin mendapatkan layanan Kesehatan dengan aman dan tepat tanpa perlu ke rumah sakit karena keterbatasan kondisi fisik. Fadhil memiliki behaviors yaitu minta tolong orang terdekat, istirahat di rumah, dan mengobati dengan obat yang ada. Namun pada kenyataannya, Fadhil menemukan beberapa pain points antara lain; mobilitas terbatas karena kondisi fisik, terlalu bergantung dengan orang lain, dan tidak mendapatkan penanganan yang cepat dari ahli.

\subsection{Analisis Permasalahan dan Kebutuhan (Define)}

Pada tahap define, ditemukan masalah utama yang dapat ditindaklanjuti dan dijadikan fokus dalam memberikan solusi. Dilakukan analisis dan pengolahan masalah yang telah didapatkan pada tahap empathize menggunakan empathy map dan point-of-view untuk menentukan masalah utama yang dijadikan fokus dalam penelitian dan dapat diselesaikan dengan solusi pada tahap selanjutnya. Empathy map adalah bentuk visualisasi yang digunakan untuk membantu menambah pemahaman tentang kebutuhan pengguna dan menjadi referensi atau pertimbangan dalam mengambil sebuah keputusan (Nielsen Norman Group, 2018). Empathy map terbagi menjadi empat kuadran yaitu Says, Thinks, Does, dan Feels. Kuadran says berisikan apa yang pengguna katakan, kuadran thinks berisikan apa yang pengguna pikirkan, kuadran does berisikan apa yang pengguna lakukan, dan kuadran feels berisikan apa yang pengguna rasakan. Tabel 1 merupakan empathy map tenaga kesehatan.

Tabel 1. Empathy Map Tenaga Kesehatan

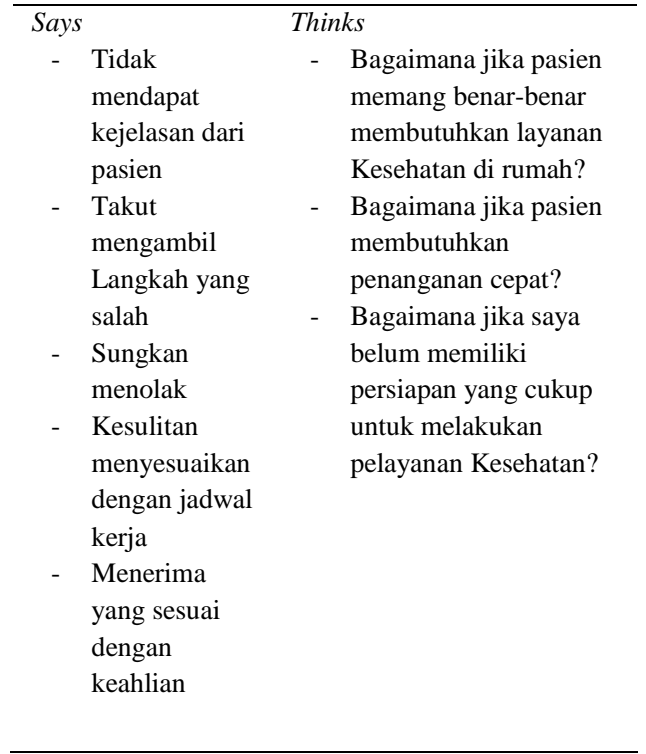




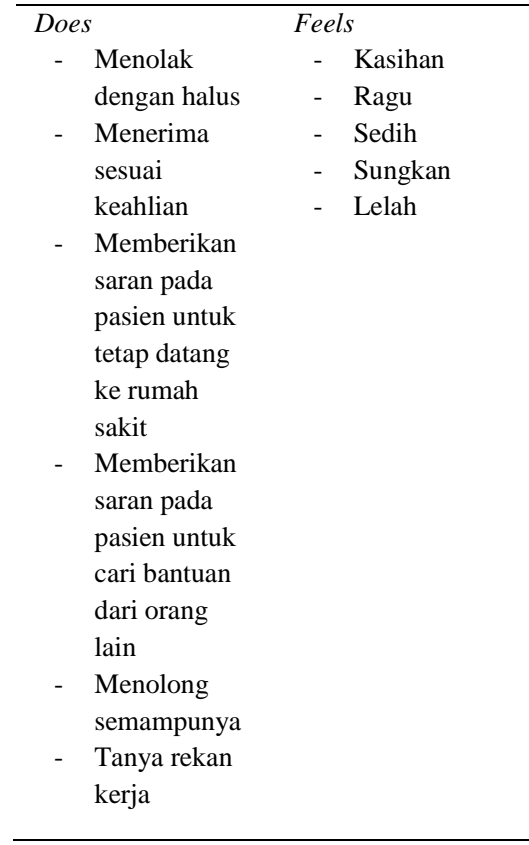

Selanjutnya dilakukan POV yang merupakan proses untuk menentukan problem statement yang akan diselesaikan melalui solusi desain dengan melihat sudut pandang pengguna. Problem statement digunakan untuk mempermudahkan tahap ideate, karena solusi desain yang dirancang sesuai dengan problem statement yang telah dibuat. Hasil point of view yang berupa problem statement juga dibahas untuk membahas kembali terkait urgensi, pengaruh, dan kapabilitas Rumah Sakit Semen Gresik. Problem statement terdiri dari tiga elemen yaitu user, need, dan insight (Interaction Design Foundation, 2019). Tabel 2 merupakan salah satu problem statement untuk pengguna pasien.

Tabel 2. Problem Statement Pasien

\begin{tabular}{cl}
\hline Kode & Problem Statement \\
\hline PS_01 & Pengguna yang ingin mendapatkan layanan \\
& kesehatan membutuhkan layanan kesehatan \\
& dengan informasi yang jelas karena hal \\
& tersebut dapat mempermudah pengguna \\
& untuk mendapatkan layanan kesehatan \\
& dengan tepat dan terhindar dari kesalahan \\
& dalam memilih layanan. \\
\hline
\end{tabular}

\section{DESAIN SOLUSI}

\subsection{Menentukan Solusi (Ideate)}

Pada tahap ideate dihasilkan beberapa solusi desain yang didapatkan melalui brainstorming yang nantinya solusi paling tepat akan dipilih menggunakan post-it voting. Brainstorming yang dilakukan didasari oleh problem statement pada tahap define. Dengan pengembangan solusi, dapat dilakukan pemecahan masalah dengan mendapatkan solusi yang paling tepat untuk diimplementasikan (Interaction Design Foundation, 2019). Tabel 3 merupakan hasil brainstorming dari salah satu problem statement untuk pengguna pasien.
Tabel 3. Hasil Brainstorming Pengguna Pasien

\begin{tabular}{|c|c|}
\hline Kode & Hasil Solusi dari Brainstorming \\
\hline PS_01 & $\begin{array}{ll}\text { - } & \text { Memberikan keterangan atau penjelasan } \\
\text { - } & \text { Mada tiap layanan kesehatan } \\
\text { Menampilkan harga tiap layanan } & \text { kesehatan } \\
\text { - } & \text { Menampilkan informasi terkait } \\
\text { - } & \text { Tesehatan } \\
\text { - } & \text { Menampicine (konsultasi online) } \\
\end{array}$ \\
\hline
\end{tabular}

Setelah beberapa solusi dikumpulkan, selanjutnya dilakukan pemilihan solusi yang paling tepat untuk digunakan. Post-it voting merupakan metode yang digunakan dalam pemilihan solusi. Dalam post-it voting, dipilih tiga sampai empat pilihan solusi yang paling sesuai. Solusi dituliskan dalam lembar post-it yang kemudian diberi tanda apabila solusi tersebut dipilih. Solusi yang memiliki tanda paling banyak berarti menjadi solusi yang banyak dipilih yang kemudian akan diimplementasikan pada tahap selanjutnya. Contoh hasil post-it voting dapat dilihat pada Tabel 4.

Tabel 4. Hasil Post-it Voting

\begin{tabular}{cll}
\hline $\begin{array}{c}\text { Kode } \\
\text { Problem } \\
\text { Statement }\end{array}$ & Kode Solusi & \multicolumn{1}{c}{ Problem Statement } \\
\hline PS_01 & S_01 & $\begin{array}{l}\text { Memberikan keterangan } \\
\text { atau penjelasan pada tiap } \\
\text { layanan kesehatan. } \\
\text { Menampilkan harga tiap } \\
\text { layanan kesehatan. } \\
\text { Menampilkan informasi } \\
\text { terkait kesehatan. }\end{array}$ \\
\hline
\end{tabular}

\subsection{Merancang Solusi (prototype)}

Perancangan solusi dibuat dengan prototyping yang terbagi menjadi dua jenis yaitu prototype lowfidelity dan prototype high-fidelity. Prototype lowfidelity adalah gambaran awal sebuah produk yang akan dibuat dengan ketelitian yang masih rendah (Interaction Design Foundation, 2020). Pada prototype low-fidelity terdapat beberapa bentuk yang berbeda dengan desain akhir produk, tidak lengkap, masih belum menggunakan warna selain hitam, putih atau abu-abu namun tetap memiliki kemiripan dengan desain akhir. Pada penelitian ini terdapat dua prototype low-fidelity yaitu untuk aplikasi HomeCare dan aplikasi HomeCare Giver. Prototype low-fidelity aplikasi HomeCare yang dapat dilihat pada Gambar 3 dan prototype low-fidelity aplikasi HomeCare Giver yang dapat dilihat pada Gambar 4. 


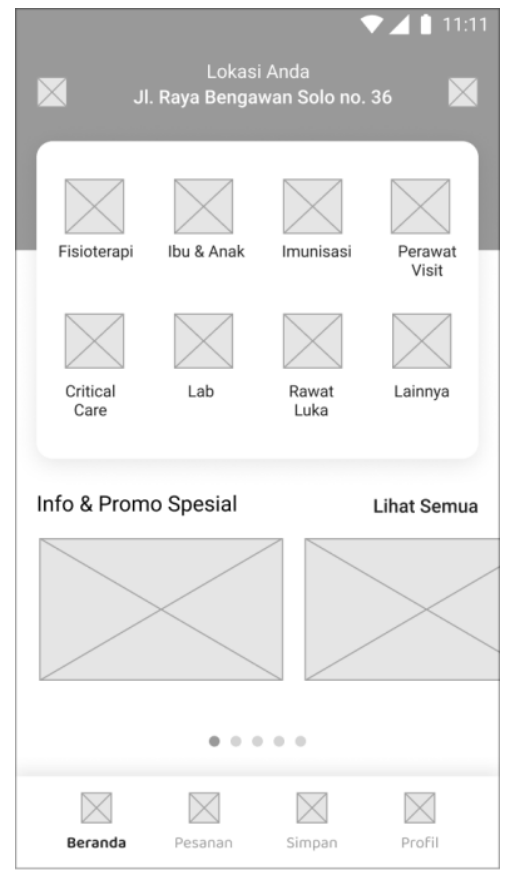

Gambar 3. Prototype Low-fidelity HomeCare

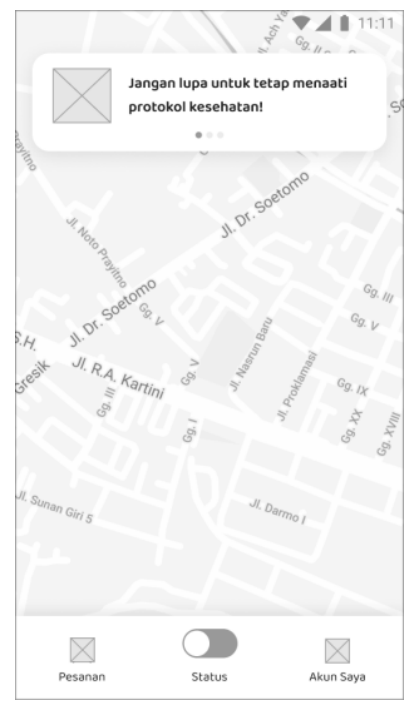

Gambar 4. Prototype Low-fidelity HomeCare Giver

Setelah itu dibuat pula User flow yang merupakan serangkaian tahap yang dilakukan oleh pengguna untuk mencapai suatu tujuan. User flow menjelaskan tentang halaman, logika, dan aksi yang dibutuhkan untuk mencapai tujuan (Handley, 2018). Setelah pembuatan user flow, dilanjutkan dengan pembuatan Prototype high-fidelity yang merupakan visualisasi yang lebih terlihat mendekati dengan produk yang akan dibuat. Hasil dari prototype highfidelity juga nantinya akan diuji pada tahap selanjutnya untuk mendapatkan feedback dari pengguna mengenai solusi yang sudah dibuat. Prototype high-fidelity aplikasi HomeCare yang dapat dilihat pada Gambar 5 dan prototype highfidelity aplikasi HomeCare Giver yang dapat dilihat pada Gambar 6.

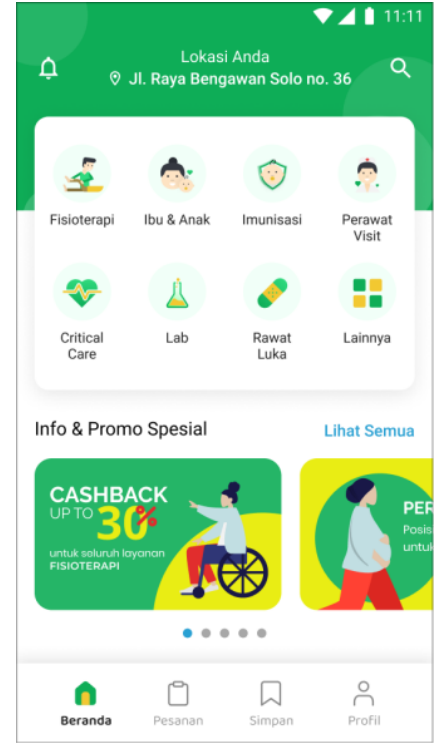

Gambar 5. Prototype High-fidelity HomeCare

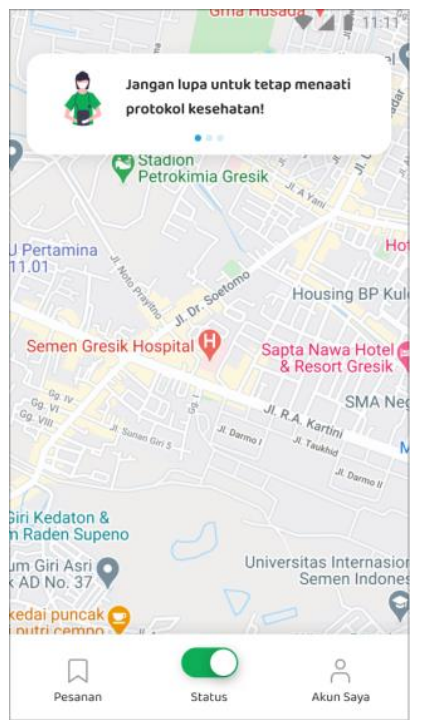

Gambar 6. Prototype High-fidelity HomeCare Giver

\section{EVALUASI DESAIN SOLUSI (TEST)}

Pada tahap test, solusi desain yang telah dibuat pada tahap sebelumnya diuji dan dievaluasi oleh calon pengguna. Tahap test bertujuan agar dapat diketahui apakah solusi desain sudah menyelesaikan masalah dan sesuai harapan pengguna atau masih memerlukan perubahan pada solusi yang ditawarkan. Pengujian pada tahap ini menggunakan metode pengukuran UEQ agar dapat diketahui apakah aplikasi tersebut sudah memberikan pengalaman penggunaan yang baik bagi penggunanya. Menurut Schrepp yang dikutip oleh Putro, S. (2019), produk atau layanan yang dievaluasi menggunakan UEQ dapat memiliki hasil yang stabil apabila menggunakan responden 20-30 orang, sehingga pada penelitian ini terdapat 20 responden untuk aplikasi HomeCare dan 20 responden untuk aplikasi HomeCare Giver. 


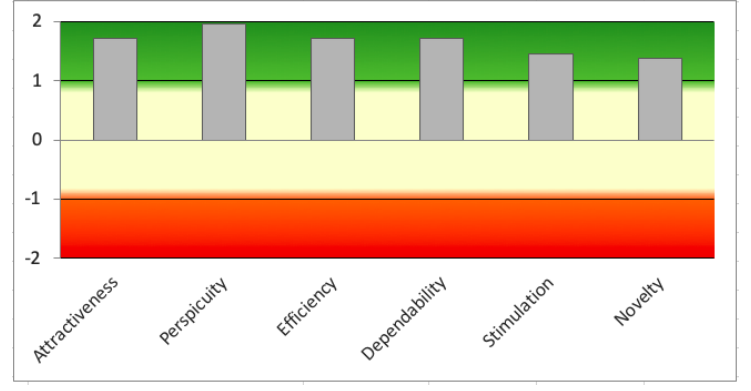

Gambar 7. Grafik Nilai Skala UEQ HomeCare

Hasil mean untuk setiap skala UEQ pada aplikasi HomeCare dapat dilihat pada Gambar 7. Untuk Untuk skala attractiveness memiliki nilai rata-rata 1,717 , skala perspicuity memiliki nilai ratarata 1,963 , skala efficiency memiliki nilai rata-rata 1,713, skala dependability memiliki nilai rata-rata 1,725 , skala stimulation memiliki nilai rata-rata 1,463, dan skala novelty memiliki nilai rata-rata 1,388. Dari nilai rata-rata tersebut, skala perspicuity memiliki nilai mean tertinggi, dan untuk skala novelty memiliki nilai mean terendah. Dari penjelasan sebelumnya maka desain aplikasi HomeCare memiliki user experience yang baik.

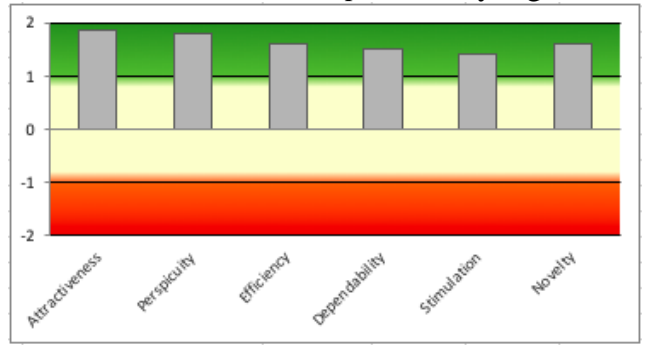

Gambar 8. Grafik Nilai Skala UEQ HomeCare Giver

Selain itu hasil mean untuk setiap skala UEQ pada aplikasi Home Care Giver dapat dilihat pada Gambar 8. Untuk skala attractiveness memiliki nilai rata-rata 1,867 , skala perspicuity memiliki nilai ratarata 1,800 , skala efficiency memiliki nilai rata-rata 1,600, skala dependability memiliki nilai rata-rata 1,525 , skala stimulation memiliki nilai rata-rata 1,400, dan skala novelty memiliki nilai rata-rata 1,625. Dari nilai rata-rata tersebut, skala attractiveness memiliki nilai mean tertinggi, dan untuk skala stimulation memiliki nilai mean terendah. Selanjutnya terdapat grafik yang menggambarkan mean dari tiap skala UEQ. Dari nilai rata-rata tersebut, skala perspicuity memiliki nilai mean tertinggi, dan untuk skala novelty memiliki nilai mean terendah. Dari penjelasan sebelumnya maka desain aplikasi HomeCare Giver memiliki user experience yang baik.

\section{KESIMPULAN DAN SARAN}

\subsection{Kesimpulan}

Berdasarkan penelitian yang telah dilakukan terkait perancangan user experience pada aplikasi mobile HomeCare Rumah Sakit Semen Gresik, maka dapat disimpulkan bahwa permasalahan yang dialami oleh Rumah Sakit Semen Gresik yaitu, kondisi pandemi saat ini membuat Rumah Sakit Semen Gresik mengalami penurunan jumlah pasien karena takut untuk datang ke rumah sakit, sehingga Rumah Sakit Semen Gresik ingin mempermudah pasien dengan memberikan layanan berobat di rumah. Rumah Sakit Semen Gresik membutuhkan dua aplikasi yang dapat memfasilitasi proses pelayanan kesehatan yang dapat dilakukan di rumah pasien yaitu HomeCare dengan target pengguna pasien Rumah Sakit Semen Gresik dan HomeCare Giver dengan target pengguna tenaga kesehatan Rumah Sakit Semen Gresik, Rumah Sakit Semen Gresik membutuhkan rancangan pengalaman pengguna pada aplikasi yang akan dibuat untuk layanan berobat di rumah, agar aplikasi tersebut dapat memberikan kenyaman serta membuat pasien menggunakan aplikasi tersebut secara berulang.

Solusi desain yang terpilih untuk aplikasi HomeCare dengan pengguna pasien yaitu memberikan keterangan atau penjelasan pada tiap layanan kesehatan, menampilkan harga tiap layanan kesehatan, menampilkan informasi terkait kesehatan, dapat melakukan pemesanan layanan kesehatan untuk saat ini dan dijadwalkan, menyediakan fitur permintaan khusus untuk pengguna, homepage menampilkan layanan kesehatan yang mudah diakses, menampilkan status pesanan pengguna, terdapat fitur notifikasi untuk pemberitahuan pengguna, menyediakan media komunikasi pengguna dan tenaga kesehatan. Selain itu, solusi yang terpilih untuk aplikasi HomeCare Giver dengan pengguna tenaga kesehatan yaitu menampilkan alamat pasien dan arahan, menampilkan informasi layanan yang dibutuhkan pasien, menyediakan media komunikasi pengguna dengan pasien, dapat mengatur status untuk tidak bertugas (tidak menerima pesanan), menampilkan pesanan yang sudah diterima tenaga kesehatan, menampilkan jarak dan estimasi waktu pengguna untuk sampai ke lokasi pasien, menampilkan informasi terkait penilaian kinerja pengguna, menampilkan informasi riwayat layanan yang telah dilakukan pengguna, menampilkan informasi pendapatan pengguna. Pembuatan desain solusi juga didasari oleh Google Material Design, selain itu terdapat beberapa komponen yang juga didasari oleh artikel mengenai User Interface Design Best Practices for Medical and Healthcare Apps mengingat aplikasi yang dirancang adalah aplikasi kesehatan.

Kemudian dilakukan pengukuran rancangan desain solusi untuk menilai apakah rancangan desain solusi sudah sesuai dengan kebutuhan dan permasalahan yang ada menggunakan User Experience Questionnaire (UEQ). Didapatkan nilai rata-rata tiap skala UEQ untuk aplikasi HomeCare yang berada pada kategori positif dengan nilai tiap skala yaitu skala attractiveness memiliki nilai rata- 
rata 1,717 , skala perspicuity memiliki nilai rata-rata 1,963 , skala efficiency memiliki nilai rata-rata 1,713 , skala dependability memiliki nilai rata-rata 1,725 , skala stimulation memiliki nilai rata-rata 1,463 , dan skala novelty memiliki nilai rata-rata 1,388. Pada benchmark UEQ, seluruh skala UEQ pada aplikasi HomeCare berada pada kategori baik (good) kecuali skala dependability yang berada pada kategori sangat baik (excellent). Selanjutnya didapatkan nilai rata-rata tiap skala UEQ untuk aplikasi HomeCare Giver yang berada pada kategori positif dengan nilai tiap skala yaitu skala attractiveness memiliki nilai rata-rata 1,867 , skala perspicuity memiliki nilai rata-rata 1,800 , skala efficiency memiliki nilai rata-rata 1,600 , skala dependability memiliki nilai rata-rata 1,525 , skala stimulation memiliki nilai rata- rata 1,400 , dan skala novelty memiliki nilai rata-rata 1,625 . Pada benchmark UEQ, seluruh skala UEQ pada aplikasi HomeCare berada pada kategori baik (good) kecuali skala attractiveness dan novelty yang berada pada kategori sangat baik (excellent).

\subsection{Saran}

Hasil penelitian yang telah dilakukan diharapkan dapat berguna untuk Rumah Sakit Semen Gresik dalam memberikan layanan kesehatan HomeCare yang dapat memberikan kenyamanan dan kegunaan pada penggunanya. Selain itu saran yang dapat diberikan terhadap penelitian selanjutnya yaitu, perlu dilakukan update pada rancangan pengalaman pengguna pada aplikasi HomeCare serta HomeCare Giver apabila terdapat perubahan atau evaluasi dari layanan yang disediakan oleh Rumah Sakit Semen Gresik serta kebutuhan baru yang diperoleh dari pengguna.

\section{DAFTAR PUSTAKA}

GARRET, J. J., 2003. The Elements of User Experience. 2nd Edition ed. Berkeley: New Riders.

HANDLEY, A., 2018. User flow is the new wireframe.

[Online]

Tersedia di: https://uxdesign.cc/when-touse-user-flows-guide-8b26ca9aa36a [Diakses pada 24 November 2020].

INTERACTION DESIGN FOUNDATION, 2019. Stage 2 in the Design Thinking Process: Define the Problem and Interpret the Results.

[Online]

Tersedia di: https://www.interactiondesign.org/literature/article/stage-2-in-thedesign-thinking-process-define-theproblem-and-interpret-the-results [Diakses pada 14 Oktober 2020].

INTERACTION DESIGN FOUNDATION, 2019. Stage 3 in the Design Thinking Process: Ideate.

[Online]

Tersedia di: https://www.interaction- design.org/literature/article/stage-3-in-the-

design-thinking-process-ideate

[Diakses pada 14 Oktober 2020].

INTERACTION DESIGN FOUNDATION, 2020. Stage 1 in the Design Thinking Process: Empathise with Your Users. [Online] Tersedia di: https://www.interactiondesign.org/literature/article/stage-1-in-thedesign-thinking-process-empathise-withyour-users

[Diakses pada 14 Oktober 2020].

INTERACTION DESIGN FOUNDATION, 2020. Stage 4 in the Design Thinking Process: Prototype.

[Online] Tersedia di: https://www.interactiondesign.org/literature/article/stage-4-in-thedesign-thinking-process-prototype [Diakses pada 14 Oktober 2020].

INTERACTION DESIGN FOUNDATION, 2020. Stage 5 in the Design Thinking Process: Test.

[Online]

Tersedia di: https://www.interactiondesign.org/literature/article/stage-5-in-thedesign-thinking-process-test [Diakses pada 15 Oktober 2020].

ISO 9241-210, 2010. Ergonomics of human-system interaction - Part 210: Human-centred design for interactive systems. s.1.:s.n.

KUSUMAWARDANI, N. dkk., 2015. Penelitian Kualitatif di Bidang Kesehatan. 1st Edition ed. Sleman: PT Kanisius.

NIELSEN NORMAN GROUP, 2015. Personas Make Users Memorable for Product Team Members.

[Online]

Tersedia di: https://www.nngroup.com/articles/persona/ [Diakses pada 5 Oktober 2020].

NIELSEN NORMAN GROUP, 2018. Empathy Mapping: The First Step in Design Thinking. [Online] Tersedia di: https://www.nngroup.com/articles/empathy -mapping/

[Diakses pada 5 Oktober 2020].

PLATTNER, H., MEINEL, C. \& LEIFER, L., 2011. Design Thinking Understand - Improve Apply. Berlin: Springer.

PUTRO, S., KUSRINI \& KURNIAWAN, M. P., 2019. Penerapan Metode UEQ dan Cooperative Evaluation. Creative Information Technology Journal, VI(1), pp. 27-37.

RAZI, A. A., MUTIAZ, I. R. \& SETIAWAN, P., 2018. Penerapan Metode Design Thinking Pada Model Perancangan UI/UX Aplikasi Penanganan Laporan Kehilangan Dan Temuan Barang Tercecer. Jurnal Desain Komunikasi Visual, III(2), pp. 75-93.

SCHREPP, M., 2019. User Experience Questionnaire Handbook. [Online] 
1066 Jurnal Teknologi Informasi dan Ilmu Komputer (JTIIK), Vol. 8, No. 5, Oktober 2021, hlm. 1057-1066

Tersedia di: $\quad$ https://www.ueqonline.org/Material/Handbook.pdf [Diakses pada 1 November 2020].

SCHREPP, M., HINDERKS, A. \& THOMASCHEWSKI, J., 2017. Construction of a Benchmark for the User Experience Questionnaire (UEQ). International Journal of Interactive Multimedia and Artificial Intelligence, IV(4), pp. 40-44.

SUCAHYO, Y., 2020. Penggalian Informasi Terkait Rumah Sakit Semen Gresik [Interview] (11 Agustus 2020).
TIAN, M., ZHANG, X. \& ZHANG, J., 2020. mHealth as a health system strengthening tool in China. International Journal of Nursing Science, VII(1), pp. S19-S22.

WULANDARI, I. R. \& FARIDA, L. D., 2018. Pengukuran User Experience pada ELearning di Lingkungan Universitas Menggunakan User Experience Questionnaire (UEQ). Jurnal Mantik Penusa, II(2), pp. 146-151. 